\title{
XXIX. On the composition of the gold from California
}

\section{T.H. Henry Esq. F.R.S.}

To cite this article: T.H. Henry Esq. F.R.S. (1849) XXIX. On the composition of the gold from California, Philosophical Magazine Series 3, 34:228, 205-207, DOI:

10.1080/14786444908646211

To link to this article: http://dx.doi.org/10.1080/14786444908646211

曲 Published online: 30 Apr 2009.

Submit your article to this journal $[\pi$

Џ Article views: 3

Q View related articles $₫$ 


\section{[ 205$]$}

XXIX. On the Composition of the Gold from California. By'T. H. HENRY, Esq., F.R.S.*

GOLD as found in nature is never chemically pure, being G combined with variable proportions of silver and traces of jron and copper, and occasionally it occurs with palladium and also with tellurium.

The amount of silver was found by Boussingault in a series of analyses of the native gold of Columbia to vary between 2 and 35 per cent., from which he drew the conclusion that the gold and silver were combined in atomic proportions, 1 atom of silver being constantly combined with more than 1 atom of gold. The specimen containing 35 per cent. of silver he considered to be a compound of 1 atom of silver and 2 atoms of gold, $\mathrm{Ag} \mathrm{Au}{ }^{2}$, and that containing 2 per cent. of silver 1 atom of silver and 12 gold, $\mathrm{Ag} \mathrm{Au}{ }^{12}$.

This view of Boussingault was controverted by Gustav Rose on his return from his celebrated journey to the Ural Mountains theoretically, on the ground that gold and silver were isomorphous bodies, and such substances are not generally met with combined in atomic proportion. "It would be as remarkable as if antimony, arsenic and tellurium were found combined in atomic proportion," he remarks $\dagger$; " but as isomorphous substances do sometimes occur combined in atonic proportion, as in bitterspar, diopside, \&c., the only remarkable result of the analyses of Boussingault is, that the gold and silver should be constantly so combined;" and experimentally by the analyses of several specimens of native gold from the Ural Mountains, in the greater number of which no such definite composition existed.

The purest specimen analysed by Rose contained 98.96 per cent. of gold and 0.16 per cent. of silver; the others contained from 60 to 94 per cent. of gold.

The gold from California, a small quantity of which I obtained from Mr. Tennant of the Strand, was taken from a quantity of about $60 \mathrm{lbs}$. weight, and was considered a fair average sample of the whole: the greater part of it was in the form of flattened grains or spangles, varying from $\frac{1}{2}$ th of a grain to 2 or 3 grains in weight; one piece however weighed upwards of 30 grains: the surface was rough and irregular, with minute portions of siliceous matter imbedded in it. The specific gravity of a number of the smaller grains taken together by the bottle was 15.96; an analysis was made of these

- Communicated by the Author.

+ Poggendorff's Annalen, vol, xxïi, p. 164. 
by treating them with aqua-regia, separating the chloride of silver, after dilution, by decantation of the solution of gold, and the chloride of silver, after having been well washed, dried and weighed, was dissolved in ammonia, leaving a white siliceous residue, but no gold. The solution of the gold was, after the destruction of the nitric acid by heat and hydrocbloric acid, digested with oxalic acid until all the gold was precipitated; the acid solution from the precipitated gold was treated with sulphuretted hydrogen; the precipitate of sulphuret of copper produced was ignited strongly, the metal estimated from the oxide and a minute button of metallic copper was procured from this by the blowpipe. After the precipitation of the copper, the solution was evaporated to dryness, the oxalic acid was expelled by heat, leaving a minute quantity of chloride of iron*, which was dissolved in water acidulated by hydrochloric acid and precipitated by ammonia. The gold precipitated by the oxalic acid was entirely dissolved by aqua-regia. In this manner these grains were found to be composed of per cent.-

Or after abstraction of siliceous matter.

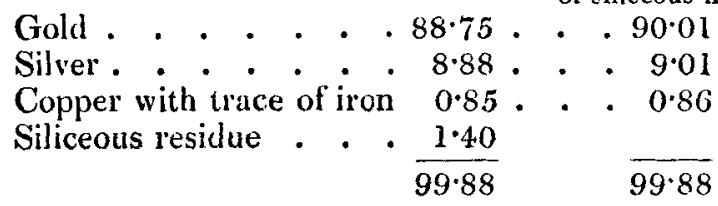

The larger piece or "pépite" weighed 30.92 grains, and its specific gravity was $15^{\circ} 63$. After being flattened out on a polished steel anvil until it appeared free from foreign matter and gently ignited, it weighed 30.24 grains, and the specific gravity was now found to be $16 \cdot 48$.

10.96 grains, mostly of this larger piece, were analysed in the manner described above, and were found to consist of in 100 parts, -

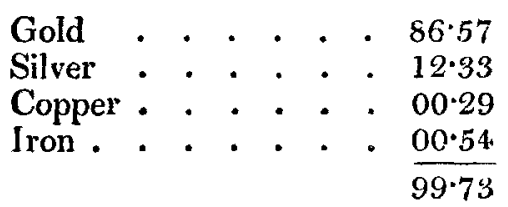

0.688 grain of this larger mass, assayed by the blowpipe by the method described by Plattnert, gave $86^{\circ} 93$ per cent. gold; and a very thin spangle, which weighed $0.483 \mathrm{gr}$, and after

* Unless the oxalic acid has been prepared by sublimation, a small quan. tity of carbonate of lime will be left after dissipation of the acid.

+ Probirkunst mit dem Löthrohre. Leipzig, 1847. 
fusion and separation of the siliceous matter 4.61 , gave $85^{\circ} 03$ per cent.

I could detect no platinum, palladium, or any of the metals usually combined with them, such as osmium, iridium, \&c., in this gold; but the small amount at my disposal would not allow me to employ a quantity sufficient to enable me to pronounce absolutely on the absence of any traces of them.

The remark of Dumas (Traité de Chimie appliquée aux Arts, tome iv. p. 434), that the proportions of gold and silver are so nearly constant in the mineral from the same locality (gisement) that the assayers know the composition when they have ascertained the precise locality which furnished it, is not confirmed by the above analyses, in which the gold varies from 85 to 90 per cent., nor indeed by those of G. Rose, of four specimens of gold from the same spot (Boruschka), which contained respectively $5 \cdot 23,8 \cdot 35,9 \cdot 02$ and 16.15 per cent. of silver.

This gold has very nearly the colour of the pure metal; after fusion however it becomes of a brass-yellow colour. This fact, together with the appearance of the grains under the microscope, would almost induce one to believe that the surface of the grains was purer or "finer" than the interior, and that a portion of the silver had been removed from the surface by some chemical agent in nature. Prof. G. Rose, at the end of his memoir already quoted, refers to the opinion prevalent both in the Ural and at St. Petersburg, that the gold from the washings is purer than that from the mines, and appears successfully to combat both this opinion and the speculations of Férussac, who would account for it by the action of sea-water, \&c.; but I must refer the reader to his memoir for his arguments, which are of great interest.

XXX. On the Geological Structure of the Alps, Carpathians and Apennines, more especially on the transition from Secondary to Tertiary Types and the existence of vast Eocene Deposits in Southern Europe. By Sir Roderick Impey MurcuIson, F.R.S., V.P.G.S., \&c.; Mem. Imp. Ac. Sciences of St. Petersburgh, Corresp. Member of the Academies of Paris, Berlin, Turin, \&c.*

THIS memoir, chiefly the result of the author's last excursion on the Continent, consists of three parts, the first of which is an en. deavour to bring up to the present standard of knowledge the work on the Eastern Alps, published long ago by Prof. Sedgwick and him-

* Abstract of a Memoir read before the Geological Society Dec. 13, 1848, and Jan. 17, 1849. 